\title{
LA CIUDADANÍA DE LA UNIÓN EUROPEA: NOVEDADES DESDE LISBOA Y LUXEMBURGO
}

\author{
Marie-José Garot \\ THE CITIZENSHIP OF THE EUROPEAN UNION: \\ NEWS FROM LISBON AND LUXEMBOURG
}

\section{RESUMO}

El Tratado de Lisboa, siguiendo la fallida Constitución EUROPEA, HA INTRODUCIDO UN NUEVO títULO II EN EL TRATADO DE LA UNIÓN EUROPEA, LLAMADO "DISPOSICIONES SOBRE LOS PRINCIPIOS DEMOCRÁTICOS" QUE PARECE COMPLETAR LAS YA EXISTENTES DISPOSICIONES SOBRE LA CIUDADANÍA EUROPEA. UNA NUEVA CONCEPCIÓN DEL CIUDADANO EUROPEO SE EMPIEZA A DIBUJAR, DISTINTA DE LA HASTA AHORA CONOCIDA.

Además, LA RECIÉN JURISPRUdencIa del TRIBUnal de JUSTICIA DE LA UNIÓN EUROPEA HA REFORZADO A SU VEZ LA CIUDADANÍA EUROPEA QUE APARECE CADA Día MÁS COMO EL "Estatuto de los nacionales de los Estados miembros", INCLUSO EN SITUACIONES PURAMENTE INTERNAS.

\section{PALAVRAS-CHAVE}

CIUdAdANía EUROPEA, NACIONALIDAd, PARTICIPACIÓN POLÍTICA, SITUACIÓN PURAMENTE INTERNA.

\author{
ABSTRACT \\ THE LISBON TREATY, IN LINE WITH THE FAILED EUROPEAN \\ CONStitution, INTRODUCED A NEW TitLE II IN THE TREATY ON \\ the European Union, called "Provisions on Democratic \\ PRINCIPLES", THAT SEEMS TO COMPLEMENT THE ALREADY \\ EXISTING PROVISIONS ON EUROPEAN CITIZENSHIP. A NEW \\ CONCEPTION OF THE EUROPEAN CITIZEN, DISTINCT FROM \\ THE ONE ALREADY KNOWN, IS BEING DESIGNED. \\ MOREOVER, THE RECENT CASE-LAW OF THE EUROPEAN \\ COURT OF JUSTICE HAS ON ITS PART REINFORCED THE \\ EUROPEAN CITIZENSHIP THAT INCREASINGLY APPEARS AS \\ the "status of the nationals of the Member States", \\ EVEN IN PURELY INTERNAL SITUATIONS. \\ KEYWORDS \\ EUROPEAN CITIZENSHIP, NATIONALITY, POLITICAL \\ PARTICIPATION, PURELY INTERNAL SITUATION.
} s más que bien sabido que el concepto de ciudadanía europea se debe a una iniciativa española y que obtuvo un reconocimiento formal con el Tratado de Maastricht de 1992. Desde entonces y sobre todo en los años 1990, una abundante literatura floreció, no sólo jurídica sino también en ciencias políticas, sociología... La ciudadanía europea despertó muchas expectativas que la aplicación jurisdiccional, sin embargo, no cumplió. En efecto, el concepto de "ciudadanía europea" se debe entender como el "estatuto de los nacionales de los Estados miembros", es decir, como una relación jurídica especial entre los nacionales de los Estados miembros y la Unión Europea. Esta relación abre la vía de disfrute a una serie de 
derechos. Pero, esos derechos, tal y como vienen recogidos en el artículo 20 del Tratado de Funcionamiento de la Unión Europea ${ }^{1}$ (TFUE) se limitan fundamentalmente a facilitar el ejercicio del derecho a la libertad de circulación de los ciudadanos europeos. En ningún caso, desde su concepción, la ciudadanía de la Unión Europea ha sido entendida como el "estatuto político" de los ciudadanos europeos.

Sin embargo, el concepto de ciudadanía europea sigue siendo clave para el proceso de integración europea. En efecto, gracias una vez más, a la labor del Tribunal de Justicia de la Unión Europea, el concepto ha podido desplegar todos sus efectos, a pesar de las limitaciones propias de los Tratados y de la legislación secundaria (en particular la Directiva 2004/38) y llegar a ser clave para el desarrollo de una de las cuatro libertades fundamentales, la libertad de circulación de las personas.

Aunque poco o casi nada comentado, el nuevo título II del Tratado de la Unión Europea introducido por el Tratado de Lisboa podría ser clave en el desarrollo de la ciudadanía europea. Titulado "disposiciones sobre los principios democráticos", se refiere a una serie de objetivos que podrían cambiar el papel de los ciudadanos europeos, si están bien empleados: expresiones como "democracia representativa" (art. 10 TUE), o "democracia participativa" (art. 11 TUE) parecen diseñar un nuevo ciudadano europeo, mucho más activo en la formulación de su provenir europeo. En todo caso, una nueva concepción del ciudadano europeo se dibuja, distinta de la hasta ahora conocida en la esfera europea.

Nos proponemos ver en ese artículo, primero, las nuevas disposiciones introducidas por el Tratado de Lisboa, en relación con los "principios democráticos de la Unión Europea" que parecen dibujar un nuevo ciudadano europeo, actor del provenir político de su Unión Europea, aunque la actualidad europea de los últimos años parece demostrar lo contrario. Veremos en particular en esa primera parte que a pesar de los intentos para remediarlo, el proceso de integración europea sigue padeciendo de un dramático déficit democrático, que hace perder gran parte de su sentido al concepto de "ciudadanía europea" (I). En la segunda parte de ese trabajo, veremos quiénes son los elegidos a formar parte de ese cuerpo que se quiere ahora político, en particular en relación con los últimos desarrollos jurisprudenciales del Tribunal de Justicia de la Unión Europea (II). Finalmente, estudiaremos cómo se han desarrollado hasta ahora los derechos asociados al estatuto de ciudadano europeo y en particular veremos el papel clave desempeñado por el principio de no discriminación (III). Pretendemos así analizar el papel real del concepto de ciudadanía europea en el proceso de integración europea.

\section{I. ¿UN NUEVO CIUDADANO EUROPEO DESPUÉS DE LISBOA?}

\section{A. Distinguir entre nacionalidad y CiUdadanía}

Para llevar a cabo una reflexión sobre el sentido de la ciudadanía de la Unión 
Europea (es decir sobre sus fines y sus objetivos), puede ser interesante referirse, aunque brevemente, a una distinción entre dos concepciones que la historia constitucional identifica claramente: por un lado la nacionalidad y por otro la ciudadanía.

La nacionalidad se define como la relación jurídica entre una persona y su Estado, definido generalmente como un Estado Nación. La posesión de la nacionalidad determina el reconocimiento de derechos civiles, sociales y políticos. La adquisición de la nacionalidad se basa sobre criterios definidos por el Estado que generalmente se refieren al derecho de la sangre (se adquiere la nacionalidad por ser hijo de un nacionalidad) o al derecho del suelo (se adquiere la nacionalidad por su lugar de residencia o de nacimiento).

En cambio, la ciudadanía tiene una multitud de sentidos pero me referiré a la que se deriva de la siempre actual Déclaration des Droits de l'Homme et du Citoyen de 1789 que considera el ciudadano como un miembro activo de una comunidad política que tiene derechos y deberes para poder participar en el provenir de aquella. Siguiendo una rama del pensamiento político ${ }^{2}$ europeo (pensamos en concreto en J. LOCKE, J-J. ROUSSEAU entre otros) la Déclaration distingue entre los derechos del Hombre (derechos naturales) y los derechos del ciudadano (es decir los derechos que permiten al Hombre gozar de su condición de Hombre social). Según la Déclaration, el principal derecho del ciudadano es el de participar en la elaboración de la Ley, expresión de la voluntad general. Supone por lo tanto un sistema político democrático que haga posible esa participación. De allí, todos los derechos políticos que permiten elegir los representantes que van a elaborar esa Ley, la cual tanto los hombres como los ciudadanos tienen el deber de seguir. Además, supone la igualdad entre los ciudadanos. Pero, como corolario de la igualdad ante la ley existe la igualdad ante las cargas públicas: deber de defender su nación, deber de participar en las finanzas públicas...Deberes que no sólo se explican como corolario de la igualdad ante la Ley, sino que tienen la inmensa virtud de reforzar el sentimiento de pertenencia a esa comunidad política de referencia. La principal diferencia es que ésos le permiten defenderse contra los abusos del poder público (derechos en negativo podríamos decir) mientras que los derechos del ciudadano le permiten participar en el provenir de su comunidad política de referencia (derechos en positivo).

La historia constitucional moderna ha vinculado durante muchos años esos dos conceptos de nacionalidad y ciudadanía: los ciudadanos son los nacionales, hasta tal punto que esos dos conceptos son sinónimos en muchos idiomas.

Sin embargo, no hay que olvidar que se puede distinguir esos dos conceptos para poder reconocer el estatuto de ciudadano (con su connotación eminentemente política) a los no-nacionales. La historia de los Estados Unidos de América enseña experiencias muy positivas de desconexión entre los dos conceptos. ${ }^{3}$ Hoy en día, en nuestras sociedades globalizadas en las cuales las migraciones son cada vez más frecuentes, es especialmente importante permitir que los no nacionales puedan 
participar en el provenir de su comunidad de residencia. Responde a la antigua reivindicación de "no taxation without representation".

\section{B. ¿UN CIUDADANO EUROPEO ACTIVO EN SU COMUNIDAD POLÍTICA?}

\section{Un Diagnostico: LA CIUDADANía EUROPEA NO EXISTE}

Hace poco tiempo, A. MORAVCSIK ${ }^{4}$ identificaba tres discursos críticos con la legitimidad democrática del proceso de integración europea. Uno, liberal, critica a la Unión Europea por ser un "super Estado" sin contrapesos suficientes para controlar su expansión. El segundo, social demócrata, se pregunta si la Unión Europea es representativa. Ese discurso se asimila considerablemente al primero, el discurso crítico liberal pero insiste en la escasa responsabilidad política de los "decision-makers" europeos. Finalmente, el último discurso es una crítica democrática-deliberativa que deplora la pasividad de los ciudadanos europeos. Ese último discurso se sustenta no sólo en los pocos mecanismos de participación política que permiten a los ciudadanos no ser pasivos, sino también en el poco uso de esos mecanismos por su parte cuando el Derecho de la Unión les brinda la oportunidad de participar en el futuro de comunidad política, ${ }^{5}$ siguiendo esa concepción republicana de la ciudadanía.

En relación con los dos primeros discursos, varios ejemplos recientes de la historia de la integración europea pueden dar apoyo a esa tesis: pensemos primero en el proceso de elaboración del Tratado de Lisboa. Es innegable que ese Tratado es "sustancialmente" similar al Tratado de Constitución Europea, ${ }^{6}$ pero como dijo amargamente el Presidente V. GISCARD D’ESTAING (antiguo presidente de la Convención Europea que propuso el texto de Constitución para Europa), «Sólo ha cambiado el formato para evitar los referendos». Como comentamos en su día, "el Tratado de Lisboa es la Constitución disfrazada y empeorada, como si el precio que hubiera que pagar por la reforma europea fuese cerrar la caja de Pandora del debate público y volver no sólo al elitismo dominante en el origen del proceso de integración, sino también a la diplomacia secreta del siglo XIX”.7

En esta misma línea, podemos recordar también la reacción poco entusiasta (por no decir negativa) de algunos líderes europeos cuando Grecia anuncio el 31 de octubre 2011 su intención de someter a referéndum la aceptación de los medidas de recorte presupuestario propuestas por la Unión Europea y el Fondo Monetario Internacional.

Existe otra forma de ver la cuestión del déficit democrático del proceso de integración europea, complementaria de las anteriores (que fundamentalmente se refieren a la escasa legitimidad democrática de las instituciones europeas). En ese caso, hablaría de un dilema democrático que la Unión Europea sigue, sin resolver, a pesar de los intentos (en particular, como veremos enseguida con el Titulo II del TUE). Ese dilema se puede ilustrar con el mismo ejemplo del referéndum en Grecia sobre el plan de ajuste económico (pueden los Griegos rechazar un plan cuyas repercusiones van 
más allá del Estado griego) o con el ejemplo de la ratificación del Tratado de Lisboa en Irlanda ${ }^{8}$ (¿pueden 862.415 Irlandeses-los que votaron que "no” en el primer referéndum relativo a la ratificación del Tratado de Lisboa en el 2008 - bloquear la adopción de un Tratado que afecte a 500 millones de Europeos, sabiendo que para que un Tratado Europeo entre en vigor, tiene que ser ratificados por todos los Estados miembros?).

El dilema consiste entonces en combinar integración europea con democracia. ¿Cómo avanzar en el proyecto de integración europea contando con la implicación de los 500 ciudadanos europeos que deberían poder expresar su opinión positiva o negativa sobre el mismo, tomando en consideración entonces tanto las voces de la mayoría como de la minoría? Con un análisis que va mas allá del contexto Europeo, D. RODRIK 9 habla a su vez, no de un dilema, sino más apropiadamente, de un "trilema" que se basa en la imposibilidad de satisfacer tres objetivos a la vez: integración económica (habla de "Hyperglobalization"), Soberanía nacional (Estado-Nación) y democracia (supranacional se entiende). En el mejor de los casos, se pueden satisfacer dos de esos tres objetivos pero siempre hay uno que se queda fuera. Ese modelo de análisis se puede también aplicar al proceso de integración europea y explicar (sin justificarlo) por lo tanto, el déficit democrático crónico que padece. El diagnostico del Profesor J. WEILER completa el de D. RODRIK. En una reciente entrevista a un periódico español, ha explicado: "A la gente no le gustan las medidas, pero las aceptan porque son legitimas. Europa no tiene legitimidad en su haber. ¿Por qué? Porque hay tres fuentes de legitimidad. La primera la democracia. La segunda, los resultados. La tercera es el mesianismo político, pero en el buen sentido. La gente está dispuesta a sacrificarse si les motiva un gran sueño, un futuro mejor... Las tres han colapsado... Yo soy europatriota, pero el proyecto de ciudadanía europea ha fallado”. ${ }^{10}$

\section{Un Remedio: ¿El Titulo II del Tratado de la Unión Europea?}

Sin embargo, una lectura optimista del nuevo Título II del Tratado de la Unión Europea podría hacer pensar que un nuevo ciudadano está en gestación desde el Tratado de Lisboa, para dar cabida a ese objetivo de "democracia" supranacional tal y como lo entiende D. RODRIK. Como apuntamos en la introducción, "las disposiciones sobre los principios democráticos" hacen referencia a una nueva faceta del ciudadano europea, ignorada hasta la fecha.

El artículo 9 se refiere en efecto por primera vez en un Tratado, ${ }^{11}$ al principio de igualdad de los ciudadanos europeos, declarando que "La Unión respetará en todas sus actividades el principio de igualdad de sus ciudadanos, que se beneficiarán por igual de la atención de sus instituciones, órganos y organismos". Aunque pueda parecer que ese principio se limite a una igual atención por parte de las instituciones europeas, no hay que olvidar que hasta el Tratado de Lisboa, el principio de igualdad 
se expresaba en negativo, es decir en la prohibición de toda discriminación entre nacionales de los Estados miembros, no sólo por razones de nacionalidad sino también, en particular desde el Tratado de Ámsterdam, por razón de sexo, origen racial o étnico, religión o convicciones, discapacidad, edad u orientación sexual. Como pudo decir S. ROBIN-OLIVIER, ${ }^{12}$ el principio de no discriminación, expresión del principio de igualdad, servía principalmente los objetivos del mercado interior, y en particular de las libertades fundamentales o de una mayor competencia entre agentes económicos. Ahora se puede esperar que vaya más allá de ese objetivo y sirva de cimiento a la edificación de una ciudadanía europea. ¿No se trata de hecho de un principio democrático?

A su vez, la Constitución europea reflejaba, en la tradición del pensamiento político europeo, esa concepción del principio de igualdad al servicio de una ciudadanía europea, y por lo tanto de una comunidad política. Recordemos el preámbulo, en el cual se proclamaba: "Inspirándose en la herencia cultural, religiosa y humanista de Europa, a partir de la cual se han desarrollado los valores universales de los derechos inviolables e inalienables de la persona humana, la democracia, la igualdad, la libertad y el Estado de Derecho ${ }^{13}$... [los jefes de Estado y de Gobierno] han convenido en las disposiciones [un Tratado por el que se establece una Constitución para Europa]".

Para dar expresión a ese derecho "inviolable" de la persona humana, el artículo I-45 de la Constitución Europea, titulado "Principio de igualdad democrática" enunciaba exactamente lo mismo que el actual artículo 9 del TUE. Salvo que, en el caso del articulo 9 TUE, los Estados miembros no han podido resistir a la necesidad de precisar por enésima vez que "será ciudadano de la Unión toda persona que tenga la nacionalidad de un Estado miembro. La ciudadanía de la Unión se añade a la ciudadanía nacional sin sustituirla”. A buen entendedor, pocas palabras: el derecho inviolable a la igualdad no es reclamable por los nacionales de Estados terceros, residan o no en el territorio europeo.

Después de afirmar ese principio básico de la vida democrática de la Unión (cuyo alcance es todavía difícil de valorar), el nuevo título II del TUE se refiere a otros principios: democracia representativa, democracia participativa e implicación de los parlamentos nacionales en el "buen funcionamiento de la Unión".

En cuanto a democracia representativa se refiere, el artículo 10 enuncia:

"1. El funcionamiento de la Unión se basa en la democracia representativa.

2. Los ciudadanos estarán directamente representados en la Unión a través del Parlamento Europeo. Los Estados miembros estarán representados en el Consejo Europeo por su Jefe de Estado o de Gobierno y en el Consejo por sus Gobiernos, que serán democráticamente responsables, bien ante sus Parlamentos nacionales, bien ante sus ciudadanos.

3. Todo ciudadano tiene derecho a participar en la vida democrática de la Unión. Las decisiones serán tomadas de la forma más abierta y próxima posible a los ciudadanos. 
4. Los partidos políticos a escala europea contribuirán a formar la conciencia política europea y a expresar la voluntad de los ciudadanos de la Unión”.

Nada nuevo en suma, simple proclamación de unos principios que ya existían y que reflejan las peculiaridades de la arquitectura institucional y de la legitimidad democrática, aunque indirecta de la Unión Europea. El apartado 3 se aparenta a su manera a una nueva formulación del principio de subsidiariedad, como principio democrático.

En cuanto a proclamar que los partidos políticos a escala europea son una pieza clave de la expresión de la voluntad de los ciudadanos de la Unión, poco se añade tampoco a lo ya expresado anteriormente (véanse los Tratados de Maastricht y Niza). Ni que decir tiene que los partidos políticos son en cualquier sistema democrático una pieza clave de la expresión de los ciudadanos. Según el Parlamento Europeo, "Un partido político a escala europea es una organización que sigue un programa político y está formada por partidos e individuos de distintos países y por tanto está representada en varios Estados miembros. Tal y como se afirma en el Tratado, «los partidos políticos a escala europea constituyen un importante factor para la integración en la Unión. Dichos partidos contribuyen a la formación de la conciencia europea y a expresar la voluntad política de los ciudadanos de la Unión”. ${ }^{14}$ El artículo 10.4 encuentra su desarrollo en el artículo 224 TFUE que reserva al Parlamento Europeo y al Consejo la adopción del estatuto de los partidos a escala europea. En la sesión plenaria del mes de abril, el Parlamento Europeo adoptó por una amplia mayoría una resolución ${ }^{15}$ sobre la aplicación del Reglamento 2004/2003 (a su vez modificado en 2007) relativo al estatuto y la financiación de los partidos políticos a escala europea. ${ }^{16}$ La idea es cambiar el estatuto de los partidos políticos a escala europea para que dejen de ser sólo organizaciones que agrupan a partidos nacionales y pasen a ser partidos políticos autónomos en contacto directo con los ciudadanos. De nuevo en este caso, habrá que ver cómo se desarrolla la participación de los ciudadanos en los partidos políticos a escala europea, sabiendo que hasta la fecha los partidos políticos a escala nacional siguen siendo piezas centrales de la participación política de los nacionales de los Estados miembros. ${ }^{17}$ El refuerzo de los partidos políticos a escala europea podría contribuir a elevar la participación de los ciudadanos europeos. ${ }^{18}$ Una paradoja a este respecto es notable: a medida que crecen las competencias del Parlamento Europeo, única institución europea elegida directamente por los ciudadanos europeos desde 1976, baja la participación en las elecciones al Parlamento Europeo. Lo que significa que quizás uno de los problemas de la falta de interés por la cosa pública europea no sea sólo el famoso déficit democrático sino otros factores, como podrían ser por ejemplo la "nacionalización" de esas elecciones.

En cuanto a la democracia participativa, el Tratado de Lisboa prevé en el artículo 11 del TUE, siguiendo a la letra el artículo I- 47 de la fallida Constitución 
Europea, distintos mecanismos para fomentar la participación de los ciudadanos europeos en su comunidad política de referencia:

"1. Las instituciones darán a los ciudadanos y a las asociaciones representativas, por los cauces apropiados, la posibilidad de expresar e intercambiar públicamente sus opiniones en todos los ámbitos de actuación de la Unión.

2. Las instituciones mantendrán un diálogo abierto, transparente y regular con las asociaciones representativas y la sociedad civil.

3. Con objeto de garantizar la coherencia y la transparencia de las acciones de la Unión, la Comisión Europea mantendrá amplias consultas con las partes interesadas.

4. Un grupo de al menos un millón de ciudadanos de la Unión, que sean nacionales de un número significativo de Estados miembros, podrá tomar la iniciativa de invitar a la Comisión Europea, en el marco de sus atribuciones, a que presente una propuesta adecuada sobre cuestiones que estos ciudadanos estimen que requieren un acto jurídico de la Unión para los fines de la aplicación de los Tratados.

Los procedimientos y las condiciones preceptivos para la presentación de una iniciativa de este tipo se fijarán de conformidad con el párrafo primero del artículo 24 del Tratado de Funcionamiento de la Unión Europea.

La iniciativa ciudadana europea va sin lugar a dudas en la línea de la emergencia de un espacio público europeo, además de fomentar efectivamente la democracia participativa. Supone un espacio supranacional en el cual los ciudadanos puedan debatir, identificar sus intereses e incluso luchar por ellos más allá de sus fronteras nacionales. Es también el reconocimiento de un mecanismo de democracia directa (es decir, tal y como lo preconiza la Déclaration des Droits de l'Homme et du Citoyen, se trata de una forma más de participación a la elaboración de la ley), aunque la Comisión tendrá plena discrecionalidad para seguir o no la petición ciudadana.

Los otros apartados del artículo 11 conducen también a la creación de espacio público europeo: cauces apropiados para expresar e intercambiar sus opiniones en todos los ámbitos de la actuación de la Unión; diálogo abierto, transparente y regular con las asociaciones representativas y de la sociedad civil; amplias consultas de la Comisión para garantizar la coherencia y la transparencia.

El artículo 12 hace una referencia especial al papel juzgado por los parlamentos nacionales en el "buen funcionamiento de la Unión". La introducción de ese artículo es nueva en relación con el título VI de la Constitución Europea. No deja de ser significativo que se hayan suprimido (o desplazado) los artículos sobre "interlocutores sociales y dialogo social autónomo" (art. I-48), el Defensor del Pueblo (art. I-49), "Transparencia de los trabajos de las instituciones, órganos y organismos de la Unión" (art. I-50), "Protección de datos de carácter personal" (art. I-51) y "Estatuto las iglesias y de las organizaciones no confesionales" (art. I-52), y que en cambio se haya 
introducido el articulo 12 TUE sobre el papel central de los Parlamentos nacionales en el título sobre principios democráticos. Esa incorporación da sin lugar a dudas un protagonismo importante a los parlamentos nacionales en el proceso de toma de decisión europea, colmando en parte el llamado déficit democrático atribuido entre otros factores a la poca relevancia del Parlamento Europeo, única institución europea elegida directamente por los ciudadanos europeos, en el proceso de toma de decisión europea. Está claro que la participación política de los ciudadanos europeos se concibe tanto a un nivel nacional (a través de los parlamentos nacionales) como a un nivel supranacional y tanto a través del Parlamento Europeo y a través de mecanismos de democracia directa, que a su vez colman las lagunas de competencias del Parlamento Europeo.

El Tratado de Lisboa, siguiendo en gran parte, el título VI de la Constitución Europea se refiere sin lugar a dudas a un ciudadano europeo que concibe como actor de su futuro político. Le reconoce una serie de derechos para participar en la vida democrática de la Unión Europea, presuponiendo por lo tanto que la Unión Europea es una comunidad política democrática (sin especificar su naturaleza).

No deja de sorprender que esa concepción no se refleja nada en la segunda parte del TFUE relativa a la ciudadanía europea y el principio de no discriminación. A parte de la iniciativa ciudadana, mencionada tanto en el Título II del Tratado de la Unión Europea como en la segunda parte del Tratado de Funcionamiento de la Unión Europea, ninguno de los derechos que fomentan la participación de los ciudadanos europeos en el futuro político de la Unión Europea tiene la más mínima referencia en el TFUE. Extraña concepción de la ciudadanía...

En este contexto, ¿qué les falta a los ciudadanos europeos para sentirse actores políticos de su futuro? Es notable que cuando se leen tanto el título II del TUE como la segunda parte del TFUE, el ciudadano europeo parece sólo titular de derechos, en ningún caso de obligaciones. Sin embargo, una referencia explícita a una obligación o un deber propio de los ciudadanos europeos (parafraseando el Presidente KENNEDY, podríamos decir "no te preguntes lo que la Unión Europea puede hacer por ti, sino lo que puedes hacer por ella”...) ayudaría sin lugar a dudas a reforzar una conciencia europea, ${ }^{19}$ sin la cual cualquier ciudadanía es imposible. Podría ser un trabajo social europeo para todos los jóvenes ${ }^{20}$ o el hecho de pagar un impuesto europeo. En este sentido y a pesar de que la aproximación de las políticas fiscales de los Estados miembros está muy lejos de ser conseguida, la Comisión Europea, en voz de su comisario LEWANDOWSKI, propuso en agosto de 2010 la creación de un impuesto europeo, ${ }^{21}$ propuesta retomada en abril 2011 por algunos Eurodiputados en la discusión sobre el presupuesto 2012.

Otra cuestión interesante que hay que tratar cuando hablamos de ciudadanía europea es la de la delimitación del cuerpo de ciudadanos europeos. ¿Puede haber una democracia sin demos? ¿Quienes son esos ciudadanos que forman el cuerpo político de la Unión Europea? 


\section{SER O NO SER CIUDADANO EUROPEO}

\section{A. El ciudadano europeo, nacional de un Estado miembro}

Aunque pueda parecer paradójico, la Unión Europea no interviene en la definición de sus propios ciudadanos. En efecto el artículo 20.1 TFUE dice: "se crea una ciudadanía de la Unión. Será ciudadano de la Unión, toda persona que ostente la nacionalidad de un Estado miembro"(redacción que se recogía también en el Tratado de Maastricht, de 1992). En la línea de ese artículo y para que no pueda haber ninguna duda, los Estados miembros precisaron en una declaración aneja al Tratado de Maastricht: "La conferencia declara que cuando en el Tratado Constitutivo de la Comunidad Europea se haga referencia a los nacionales de los Estados miembros, la cuestión de si una persona posee una nacionalidad determinada se resolverá únicamente remitiéndose al Derecho nacional del Estado miembro de que se trate. Los Estados miembros podrán declarar, a efectos informativos, quiénes deberán considerarse sus nacionales a efectos comunitarios mediante una declaración presentada a la Presidencia, la cual podrá modificarse en caso necesario”. Esa declaración no tiene ningún valor jurídico, puramente informativo pero los Estados miembros reiteraron en el Consejo Europeo de Edimburgo de diciembre de 1992 esa misma opinión : "Las disposiciones de la Segunda Parte del Tratado constitutivo de la Comunidad Europea relativas a la ciudadanía de la Unión otorgan a toda persona que ostente la nacionalidad de los Estados miembros derechos adicionales y protección, tal como se especifica en dicha Parte, y de ninguna forma sustituyen a la ciudadanía nacional. La cuestión de si un individuo posee la nacionalidad de un Estado miembro sólo se resolverá refiriéndola al Derecho nacional del Estado miembro interesado.”

La determinación de los nacionales de los Estados miembros se hace siguiendo normas de ius sanguinis o ius soli. Significa concretamente que será más o menos fácil adquirir la nacionalidad en un Estado miembro u otro, dependiendo de la "apertura" del derecho de la nacionalidad al ius soli y de sus procesos de naturalización. ${ }^{22}$

Esa solución que reserva a los únicos Estados miembros la posibilidad de definir los ciudadanos europeos es conforme al Derecho Internacional. Basta con leer el artículo 1 del Convenio de la Haya sobre algunas cuestiones en relación con conflictos de leyes en materia de nacionalidad ${ }^{23}$ para darse cuenta de eso: "corresponde a cada Estado determinar según su propio derecho quiénes son sus nacionales. Ese derecho debe ser reconocido por los otros Estados, en la medida en que sea coherente con los convenios internacionales, la costumbre internacional y los principios generales del derecho reconocidos en materia de nacionalidad". En la misma línea, el artículo 3.1 del Convenio Europeo ${ }^{24}$ de 1997 sobre la nacionalidad dicta: "pertenece a cada Estado determinar por su legislación quiénes son sus nacionales". 


\section{B. UNA COMPETENCIA DE LOS ESTADOS MIEMBROS NO TAN EXCLUSIVA}

Por su parte, el Tribunal de Justicia de la Unión Europea ha reafirmado esa solución en la sentencia Micheletti (1992), ${ }^{25}$ dictada poco después de la firma del Tratado de Maastricht pero antes de su entrada en vigor. Como ya es conocido, se trataba de saber si un doble nacional (ítalo-argentino, es decir con una nacionalidad no comunitaria) se podía beneficiar de las disposiciones relativas a la libertad de establecimiento en España - concretamente en Cantabria. El Tribunal recuerda la solución clásica, que reconoce una competencia exclusiva a los Estados miembros en materia de nacionalidad, y afirma por otra parte que los otros Estados miembros están obligados por la competencia exclusiva de los Estados miembros: "La determinación de los modos de adquisición y pérdida de la nacionalidad es, de conformidad con el Derecho internacional, competencia de cada Estado miembro, competencia que debe ejercerse respetando el Derecho comunitario. No corresponde en cambio a la legislación de un Estado miembro limitar los efectos de la atribución de la nacionalidad de otro Estado miembro, exigiendo requisitos adicionales para reconocer dicha nacionalidad en orden al ejercicio de las libertades fundamentales previstas en el Tratado" (apartado 10). Significa que no se pueden imponer nuevas condiciones para considerar nacional de un Estado miembro como ciudadano de la Unión Europea, siempre y cuando haya obtenido su nacionalidad siguiendo las normas vigentes en su Estado de referencia. Concretamente, en el caso de Micheletti, España no podía denegarle el beneficio de la libertad de establecimiento por considerar que su nacionalidad italiana carecía de "efectividad", noción que el Abogado General Tesauro calificó de "anclada en un período "romántico" de la vida de las relaciones internacionales".

Lo mismo ocurre en otro asunto, Chen, ${ }^{26}$ en el cual se reconoce el estatuto de ciudadana europea (y por lo tanto el beneficio de las disposiciones en materia de libre circulación de personas) a una niña nacida en Irlanda del Norte, de madre china. Su madre se fue expresamente a dar a luz a Irlanda del Norte para que su hija pudiera adquirir la nacionalidad irlandesa ${ }^{27}$ y por esa vía la ciudadanía europea y beneficiarse así de los derechos de libre circulación para poder residir posteriormente en el Reino Unido. El Tribunal consideró que, como la adquisición de la nacionalidad irlandesa era perfectamente legal, el Reino Unido debía tratar a Catherine Chen como una ciudadana europea y otorgarle el derecho de residencia en su territorio. El Reino Unido tuvo también la obligación de emitir un permiso de residencia a la madre de Catherine Chen, por estar al cuidado de una ciudadana europea menor de edad.

Aunque la solución del Tribunal es conforme al Derecho Internacional, limita finalmente la actuación de los otros Estados miembros que tienen la obligación de reconocer cualquier derecho que se derive del Derecho Europeo a todo ciudadano europeo, cualquiera sea el modo en que se ha adquirido la nacionalidad de un Estado miembro, y por 
lo tanto la ciudadanía europea. El Tribunal ha reiterado esa solución en el caso Rottmann (2009), ${ }^{28}$ incluso en un caso de adquisición fraudulenta de nacionalidad.

El Sr. Rottmann, natural austríaco por nacimiento, se instaló en Alemania, cuya nacionalidad adquirió después de varios años de residencia. Sin embargo, dio unas informaciones falsas para obtener esa nacionalidad. En cuanto Alemania se percató de eso, decidió retirarle retroactivamente la naturalización, por obtención fraudulenta de la nacionalidad alemana. El Sr. Rottmann recurrió contra esa decisión que le podía dejar apátrida, por haber tenido que renunciar a su nacionalidad austríaca para adquirir la alemana (además, ya no estaba en condiciones de recuperar su nacionalidad austriaca). Vistas las consecuencias que la decisión alemana podía conllevar sobre la condición de ciudadano europeo, el tribunal alemán, Bundesverwaltungsgericht, decidió recurrir al Tribunal de Justicia para aclarar sus dudas, en particular saber "si el Derecho de la Unión, en particular el artículo $17 \mathrm{CE}$, se opone a que un Estado miembro le revoque a un ciudadano de la Unión la nacionalidad de dicho Estado miembro adquirida de modo fraudulento mediante naturalización en la medida en que tal revocación priva al interesado de su estatuto de ciudadano de la Unión y de los derechos correspondientes, convirtiéndolo en apátrida, puesto que la adquisición de la nacionalidad de ese Estado miembro por naturalización supuso para la persona afectada la pérdida de la nacionalidad de su Estado miembro de origen" (apartado 36 de la sentencia).

Aunque el Tribunal de Justicia no le niega a Alemania el derecho a retirar una nacionalidad obtenida de manera fraudulenta, le recuerda en el apartado 45 la obligación para los Estados miembros de respetar "en el ejercicio de su competencia en materia de nacionalidad, el derecho de la Unión Europea”. Lo que justifica el control posible delTribunal Europeo, sabiendo que "cuando se trata de ciudadanos de la Unión, el ejercicio de esta competencia, en la medida en que afecte a los derechos conferidos y protegidos por el ordenamiento jurídico de la Unión, como ocurre en particular en el caso de una decisión revocatoria de la naturalización como la del asunto principal, puede ser sometido a un control jurisdiccional realizado en función del Derecho de la Unión” (apartado 48). En ese caso concreto, el Tribunal de Luxemburgo se limitó a reconocer el derecho de Alemania de retirar la nacionalidad (en virtud de un motivo de interés general), siempre y cuando fuese respetando el principio de proporcionalidad. Es decir, tomando en cuenta las consecuencias de esa decisión en relación con la familia del Sr. Rottmann, que se quedaba en situación de perder el beneficio de las disposiciones sobre libre circulación de personas (apartados 56 a 58). De allí que el Tribunal de Justicia sentenciara que "el Derecho de la Unión, en particular el artículo $17 \mathrm{CE}$, no se opone a que un Estado miembro le revoque a un ciudadano de la Unión la nacionalidad de dicho Estado miembro adquirida mediante naturalización cuando ésta se ha obtenido de modo fraudulento, a condición de que esta decisión revocatoria respete el principio de proporcionalidad.” 
La exclusión a priori de la Unión Europea (pero no del Derecho Europeo) en materia de determinación de nacionales de los Estados miembros es finalmente relativa, no sólo porque los Estados miembros tienen la obligación de respetar, tal y como recuerda el Tribunal en los asuntos Micheletti, Chen o Rottmann, el Derecho Europeo en el ejercicio de esa competencia (principio de proporcionalidad entre otros), sino también porque en materia de derecho de la nacionalidad una nueva tendencia se está dibujando. En efecto, algunos Estados miembros están incorporando disposiciones especiales en materia de naturalización para los ciudadanos europeos, considerándolos como "extranjeros especiales”. Así, Austria, Alemania, Eslovenia, Hungría, Italia y Rumania reducen considerablemente la condición de duración de residencia para los ciudadanos europeos, además de no imponer necesariamente la obligación de renunciar a su nacionalidad de nacimiento. ${ }^{29}$

Otra cuestión se refiere a la necesidad o la relevancia de obtener la nacionalidad de un Estado miembro, a la vista de los derechos que otorga el estatuto de ciudadano de la Unión Europea.

\section{El eStATUto de los NACiONALES de los Estados miembros}

La segunda parte del Tratado sobre el Funcionamiento de la Unión Europea se refiere explícitamente a los derechos conferidos a los titulares de la ciudadanía europea (art. 20 TFUE): derecho de circular y residir libremente en el territorio de los Estados Miembros; derecho de sufragio activo y pasivo en las elecciones municipales y europeas en el Estado miembro de residencia; derecho a una protección diplomática y consular en un Estado tercero; derecho de enviar peticiones al Parlamento Europeo; derecho de queja al Defensor del Pueblo Europeo; derecho de dirigirse en una de las lenguas oficiales de la Unión Europea; y derecho de iniciativa popular. El artículo 25 TFUE se refiere a la posibilidad de extender esa lista de derechos, dando por consiguiente un carácter dinámico a la ciudadanía europea. ${ }^{30}$

Además de haber recurrido de forma extensa al principio de no discriminación para extender los derechos de los ciudadanos europeos que se desplazan a otro Estado miembro, lo que más llama la atención es la nueva lectura que hace el Tribunal de Justicia de la Unión Europea del articulo 20.1 TFUE, dando a la ciudadanía europea un alcance que va mucho más allá del catálogo de derechos que el TFUE reconoce a los ciudadanos.

\section{A. LA CIUDAdANía ENTENDIDA COMO Un CATÁlOgo ABIERTO DE DERECHOS}

Como es bien sabido, el TJUE ha jugado un papel fundamental en el desarrollo de la ciudadanía europea. En el famoso asunto Rudy Gzelczyk, ${ }^{31}$ el Tribunal reconoció que la ciudadanía es "el estatuto fundamental de los nacionales de los Estados miembros". Con eso, el Tribunal ha elevado la ciudadanía europea al rango de estatuto jurídico 
de los Europeos, lo mismo que ocurre con la nacionalidad de los nacionales de los Estados miembros. En ese sentido, la "ciudadanía de la Unión se añade a la ciudadanía nacional, sin sustituirla" (art. 20.1 TFUE). ¿Qué significa ser el "estatuto jurídico de los Europeos"? Significa que los Europeos tendrán un estatuto particular (es decir serán titulares de derechos que le son propios) por el mero hecho de ser Europeos, lo que les confiere una posición especial, en relación con el resto de los ciudadanos no europeos que residen en el territorio europeo. En pocas palabras, residan donde residan, los ciudadanos europeos serán titulares de esos derechos. Desaparece así la noción de extranjero, por lo que se refiere a un nacional de un Estado miembro que reside en otro Estado miembro.

Se adquiere el estatuto de ciudadano europeo, como ya hemos apuntado, por la nacionalidad de un Estado miembro. Pero es evidente que, hasta la fecha, este estatuto no desplegaba todos sus efectos mientras no se había hecho uso del principal derecho de ello, el derecho a la libre circulación. Es sin duda el más importante de todos los derechos de ciudadanía europea. Permite a todo ciudadano europeo desplazarse, residir y trabajar (o no) en otro Estado miembro siempre y cuando se respeten las disposiciones de derecho derivado y en particular la Directiva 2004/38. Conviene recodar el artículo 7 que reconoce el derecho a la libre circulación de los ciudadanos europeos superior a tres meses, cuando se cumplen una serie de condiciones: es decir, si un ciudadano europeo no es un trabador por cuenta aneja o por cuenta propia, tendrá que desmostar que no constituye una carga excesiva para el Estado de acogida, al tener unos recursos suficientes y un seguro médico. ${ }^{32}$ El derecho se extiende a los miembros de la familia del ciudadano europeo, nacionales de un Estado miembro o no.

El derecho a la libre circulación es especialmente importante porque de su ejercicio van a depender otros derechos, como los derechos de voto en las elecciones municipales y europeas. Esos derechos permiten a los ciudadanos europeos que residen en un Estado miembro distinto del de su nacionalidad, votar y ser votado en las elecciones municipales y europeas, sin demostrar, acorde con las directivas relativas a esos derechos, un cierto nivel de integración (por la duración de la residencia). Esos derechos se definen como una aplicación, antes de nada, del principio de no discriminación: el hecho de desplazarse no debe hacer perder a los ciudadanos europeos parte de sus derechos de voto. A la vista de ese razonamiento surge inevitablemente la pregunta relativa a los derechos de voto en las elecciones nacionales. Se explica difícilmente que los ciudadanos europeos sean excluidos de su ejercicio.

En cuanto a los derechos de petición al Parlamento Europeo o de queja al Defensor de Pueblo, es verdad que se pueden ejercer sin necesidad de residir en otro Estado miembro. Permiten defenderse, o al menos hacer oír su voz, frente a las instituciones europeas o frente a los Estados miembros cuando apliquen el Derecho Europeo. 
En el mismo orden de ideas ${ }^{33}$ se inscribe el derecho a presentar una iniciativa ciudadana (art. 24 TFUE), ya visto en la primera parte de este trabajo. Hay que poner en relación el artículo 24 TFUE con el artículo 11 del TUE, que precisa el modo de ejercicio de ese nuevo derecho que la Comisión Europea, en su propuesta de Reglamento, presentó como una de las “más importantes innovaciones delTratado de Lisboa”. ${ }^{34}$ Es notable la eficacia de las instituciones europeas a la hora de adoptar las normas que regulen la iniciativa ciudadana. ${ }^{35}$

Finalmente, el artículo 23 TFUE se refiere a la protección diplomática y consular, que permite a cualquier ciudadano europeo pedir ayuda a las autoridades de un Estado miembro, distinto del suyo, en un país tercero, cuando su propio Estado no tiene ninguna representación allí. La Decisión ${ }^{36}$ de 1995 precisó los detalles de su puesta en práctica. Es un derecho simbólicamente importante porque va en el sentido de una clara desconexión entre nacionalidad y protección diplomática y consular. Refuerza la idea de una protección diplomática europea, aunque de nuevo aquí no es la Unión Europea, sino los Estados miembros, los que otorgan dicha protección. Habrá que ver cómo evoluciona ese derecho, en particular a la luz de la puesta en marcha del servicio europeo de acción exterior.

Después de analizar brevemente los derechos asociados al estatuto de ciudadano europeo, es manifiesto que tienen como finalidad tanto favorecer la libre circulación de las personas como su integración en el Estado miembro de residencia (lo que a su vez, favorece la movilidad) y reforzar la protección de los ciudadanos frente a la Administración comunitaria o a los Estados miembros cuando apliquen el Derecho Europeo.

\section{B. UNOS DERECHOS RECONOCIDOS A NACIONALES DE ESTADOS TERCEROS}

Aunque el beneficio de los derechos de la segunda parte del TFUE va dirigido en principio a los ciudadanos europeos, no hay que olvidar que muchos de esos derechos son accesibles incluso a nacionales de terceros Estados. Es decir, los derechos de la ciudadanía europea no son finalmente propios de los ciudadanos europeos. Es el caso de los derechos de petición al Parlamento Europeo y quejas al Defensor del Pueblo, cuyo beneficio el propio Tratado (art. 227 y 228 TFUE) reconoce tanto a las personas físicas como jurídicas, incluso sin nacionalidad de un Estado miembro o residencia en un Estado miembro.

Como acabamos de ver, la legislación europea y la extensa jurisprudencia del TJUE reconocen el beneficio del derecho a la libre circulación a miembros de la familia de un ciudadano europeo, no necesariamente nacionales de un Estado miembro. Pero, si se rompe la relación familiar con el ciudadano europeo o si el ciudadano pierde su derecho (por no cumplir con las condiciones del artículo 7 de la Directiva de 2004 o por razones de seguridad pública, orden público y salud pública), se extingue, aunque no de forma inmediata, también ese derecho para los miembros de la familia o ex - familia. 
En el caso de los derechos de voto, el Tribunal de Justicia ha reconocido en una sentencia controvertida, España contra Reino Unido, ${ }^{37}$ el derecho de voto en las elecciones europeas a residentes en Gibraltar sin condición de nacionalidad, poniendo en cuestión incluso la identidad de la Unión Europea, según algunos autores. ${ }^{38}$ Esa sentencia pone de manifiesto dos concepciones de la ciudadanía europea: una exclusiva de los ciudadanos europeos, nacionales de los Estados miembros, en referencia a la identidad europea y otra, más formalista en un cierto sentido, según la cual los derechos asociados a la ciudadanía europea no son exclusivos de los ciudadanos europeos y por lo tanto pueden ser abiertos a los nacionales de Estados terceros, quedando la decisión final al Estado Miembro en el cual residen esos nacionales. Es decir, se abre la vía a un reconocimiento de los derechos de ciudadanía europea, y en este caso de los derechos de voto, independientes de la nacionalidad de los beneficiarios. Es un intento de desconectar ciudadanía y nacionalidad y basar la ciudadanía en la residencia. Esa postura fue afirmada entonces por el Tribunal de Luxemburgo, dando la razón al Reino Unido, apoyado a su vez por la Comisión Europea.

\section{MÁs Allá DEL ARTículo 2o TFUE: El PRINCIPIO DE NO DISCRIMINACIÓN}

Sin embargo, además de los derechos de la segunda parte, los ciudadanos europeos pueden reclamar el beneficio del principio de no discriminación par acceder a nuevos derechos en su Estado miembro de destino. En efecto, desde la famosa sentencia Martinez Sala (1998), el principio de no discriminación ha permitido extender, casi de forma indefinida, los derechos que se reconocen a los ciudadanos europeos, más allá de los derechos enumerados en el artículo 20.1 del TFUE.

Ese principio obliga los Estados miembros a tratar todos los ciudadanos europeos que residen en su territorio de la misma manera (en los ámbitos regulados por los Tratados). Es un reconocimiento en negativo del principio de igualdad de todos los ciudadanos europeos, en la esfera de competencia de la Unión Europea. De hecho, el Tratado de Lisboa reformuló la segunda parte del Tratado de Funcionamiento de la Unión Europea para incluir las disposiciones sobre no discriminación. A partir de ahora, esa segunda parte se denomina "no discriminación y ciudadanía de la Unión Europea".

La aplicación práctica del principio de no discriminación a todos los ciudadanos europeos tiene un coste elevado para los Estados miembros (véase por ejemplo los asuntos Collins ${ }^{39}$ y Bidar). ${ }^{40}$ Los asuntos Texeira $^{41}$ y Ibrahim $^{42}$ reflejan la voluntad del Tribunal de Justicia de la Unión Europea de dar pleno reconocimiento al "estatuto de ciudadano europeo”. En el asunto Texeira, el Tribunal de Luxemburgo reconoció que acorde con el siempre vigente artículo 12 del Reglamento 1612/68, (a pesar de la directiva 2004/38), ${ }^{43}$ el padre o la madre, ciudadana europea, encargada de cuidar de los niños, nacionales de un Estado miembro, tienen derecho de residencia, independientemente del hecho de que tenga recursos suficientes y seguro medico. ${ }^{44}$ Ese derecho se deriva del derechos de sus hijos, ciudadanos europeos, a seguir sus 
estudios en el Estado miembro de residencia. En Ibrahim, el Tribunal Europeo aplico la misma solución incluso de una madre Somalí, divorciada de un ciudadano danés.

\section{LA FUERZA DEL ARTÍCULO 20 TFUE y EL ESTATUTO DE LOS NACIONALES DE LOS ESTADOS MIEMBROS}

Está claro que el principio de no discriminación ha jugado un papel clave en la extensión de los derechos de los ciudadanos europeos. Sin embargo, hasta la fecha, esos derechos "nacionales" se podían reclamar sólo en caso de desplazamiento de los ciudadanos, es decir una vez se ha hecho uso del derecho a la libre circulación.

Una sentencia reciente del Tribunal de Justicia ha "revolucionado" esta concepción, dando una fuerza al estatuto de los nacionales de los Estados miembros, desconocida hasta ahora.

En efecto, por primera vez el pasado 8 de marzo de 2011, la Gran Sala del Tribunal de Justica de la Unión Europea, ${ }^{45}$ basándose exclusivamente en el artículo 20 TFUE, reconoció un derecho de residencia y trabajo a los padres no comunitarios de unos niños, nacionales belgas y, por lo tanto, ciudadanos europeos que viven con sus padres en Bélgica. Es decir, por primera vez se reconoció un derecho de permanencia a los familiares de un ciudadano europeo en su propio Estado de origen. No se trataba como hasta ahora de extender el beneficio del derecho a la libre circulación a los familiares de un ciudadano europeo en caso de desplazamiento de este ciudadano europeo a un Estado miembro distinto del de su origen. En pocas palabras, se trataba de una "situación puramente interna", en la cual no hubo en ningún momento ningún desplazamiento.

Este caso se refería a un nacional de Colombia, el Sr. Ruiz Zambrano, al que Bélgica negó reiteradamente el estatuto de refugiado así como el derecho de residencia en el suelo belga y ordenó el abandono del país. ${ }^{46}$ A pesar de esas órdenes, el Sr. Ruiz Zambrano se quedó con su esposa colombiana en Bélgica, donde consiguió un trabajo (durante unos cinco años no seguidos) remunerado, sujeto a la "retención legal de las cotizaciones de seguridad social y al pago de las cotizaciones empresariales". Además de trabajar y ser empadronado en su ciudad de residencia, durante su estancia en Bélgica, el Sr. Ruiz Zambrano y su esposa tuvieron dos hijos (ya tenían un primer hijo nacido en Colombia), que adquirieron la nacionalidad belga por haber nacido en Bélgica y por no tener otra nacionalidad (aunque sus padres tenían la posibilidad de transmitirles su propia nacionalidad, Colombia exige a sus nacionales que residen en el extranjero, que realicen unos trámites que los Ruiz Zambrano no realizaron. Por lo tanto, los hijos Ruiz Zambrano nacidos en Bélgica no tuvieron más opción que la de adquirir la nacionalidad belga).

El litigio surgió por el hecho de que en 2005, el Sr. Ruiz Zambrano se quedó sin empleo por razones objetivas, y solicitó unas prestaciones de desempleo, que le fueron denegadas por no tener un permiso de trabajo en Bélgica. 
A pesar de esa historia procesal compleja, las cuestiones prejudiciales se resumen al hecho de saber si el Sr. Ruiz Zambrano tiene un derecho de residencia en Bélgica por el hecho de ser padre de dos nacionales belgas, ciudadanos europeos a su vez. Dicho de otra manera, si el hecho de ser padre de dos ciudadanos europeos le dan un derecho de residencia automático.

Es verdad que en asuntos recientes el Tribunal de Justicia había entreabierto una puerta en esa dirección. Recordémonos de los ya conocidos casos de Garcia Avello, ${ }^{47}$ Chen, o más recientemente Rottmann, en el cual, como ya vimos el Tribunal, en una situación aparentemente interna, aconsejó a las autoridades alemanas tomar en consideración el perjuicio que podía causar al Sr. Rottmann, antiguo nacional austríaco nacionalizado alemán, el hecho de privarle de la nacionalidad alemana (adquirida de manera fraudulenta), en relación en particular con los derechos que se derivan de la ciudadanía europea.

Sin embargo, la sentencia Ruiz Zambrano va más allá todavía, al desconectar los derechos que se derivan de la ciudadanía europea de un necesario desplazamiento para otorgarles su pleno efecto. En ese sentido, la Gran Sala siguió las conclusiones de la Abogada General E. Sharpston, aunque no basó su razonamiento en algunos derechos fundamentales tales como el respecto a la vida privada y familiar o los derechos de los niños consagrados por el Convenio Europeo de Derechos Humanos y la propia Carta de Derechos Fundamentales de la Unión Europea (aunque no en vigor en la época de los hechos), tal y como le invitaba Ms. Sharpston, ni tampoco utilizó el argumento de una posible discriminación inversa (los familiares no europeos de los ciudadanos europeos que se desplacen a Bélgica tendrían según la jurisprudencia y la Directiva 2004/38 un derecho a residir en Bélgica).

Partiendo, como en otros casos, de la premisa según la cual "la vocación del estatuto de ciudadano de la Unión es convertirse en el estatuto fundamental de los nacionales de los Estados miembros", el Tribunal considera escuetamente que "el artículo 20 TFUE se opone a medidas nacionales que tengan por efecto privar a los ciudadanos de la Unión el disfrute efectivo de la esencia de los derechos conferidos por su estatuto de ciudadano de la Unión" (apartado 42). Explica a continuación: "la negativa a conceder un permiso de residencia a una persona, nacional de un Estado tercero en el Estado miembro en el que residen sus hijos de corta edad, nacionales de dicho Estado miembro, cuya manutención asume, y la negativa a concederle un permiso de trabajo, tienen tal efecto. En efecto, debe considerarse que tal denegación del permiso de residencia tendrá como consecuencia que los mencionados menores, ciudadanos de la Unión, se verán obligados a abandonar el territorio de la Unión para acompañar a sus progenitores. Del mismo modo, si no se concede un permiso de trabajo a tal persona, ésta corre el riesgo de no disponer de los recursos necesarios para poder satisfacer sus propias necesidades y las de su familia, lo que tendrá también como consecuencia que sus hijos, ciudadanos de la Unión, se verán 
obligados a abandonar el territorio de ésta. En tales circunstancias, estos ciudadanos de la Unión se verán, de hecho, en la imposibilidad de ejercer la esencia de los derechos que les confiere su estatuto de ciudadanos de la Unión” (apartado 44).

El elemento central del razonamiento del Tribunal es sin lugar a dudas el artículo 20 TFUE que, para poder desplegar todos sus efectos, obliga a los Estados miembros a reconocer un derecho de residencia a los padres no europeos de unos ciudadanos europeos, que vivan o no en su propio Estado miembro.

La sentencia Ruiz Zambrano es quizás más importante aún por lo que no dice. Es notable la falta de referencia a la Directiva 2004/38, norma clave en materia de libre circulación de los ciudadanos europeos y de sus familiares. En otras palabras, la fuerza del artículo 20 TFUE omite cualquier referencia a la Directiva 2004/38.

¿Qué puede significar la ausencia de referencia a la Directiva 2004/38? Una interpretación optimista puede sugerir que las condiciones de solvencia económica que se requieren para que los familiares-no comunitarios se puedan beneficiar de la libre circulación no se aplican en caso de situación puramente interna. Pero de nuevo aquí habrá que ver cómo el Tribunal de Justicia desarrolla ese razonamiento, a la vez que la reacción de los Estados Miembros.

Otra duda que puede levantar el escueto razonamiento del Tribunal de Luxemburgo se refiere al hecho de saber si las condiciones de entrada y residencia de los familiares no europeos de un ciudadano europeo que reside en su propio territorio escapan a la competencia de los Estados miembros. Ese tipo de situaciones está normalmente previsto por las legislaciones nacionales en materia de política migratoria, es decir en relación con nacionales de Estados terceros. ¿Significa finalmente que entran en el ámbito material del Derecho Europeo, tratándose al fin y al cabo de los derechos de un ciudadano europeo?

No cabe duda de que la sentencia Ruiz Zambrano provocará una reacción de los Estados miembros, ya molestos con la sentencia Metock ${ }^{48}$ que de una cierta manera, limita también la competencia de los Estados miembros en materia de política migratoria, cuando hay un ciudadano europeo de por medio...

\section{CONCLUSIÓN}

A pesar del paso importante dado por la sentencia Ruiz Zambrano, podemos concluir sin temor que el concepto de ciudadanía europea se aparenta más a una nacionalidad europea que a una ciudadanía europea, en el sentido "republicano" y político de la palabra. La actual ciudadanía europea sería un estatuto al servicio de los fines del Tratado y nada más. La aportación de la ciudadanía europea al proceso de integración europea se manifestaría entonces sólo en relación con los derechos de libre circulación, de los cuales, recordémoslo, hacen uso sólo unos 10 millones de ciudadanos europeos. 
Sin embargo, gracias en parte a las nuevas disposiciones del Tratado de la Unión Europea, podemos esperar que un nuevo ciudadano emerja, ciudadano actor clave de su provenir político europeo y no simple titular de derechos. Lo que cambiaría también el rostro de la propia Unión Europea. Podemos pensar quizás, como el Abogado General Miguel Maduro, en las conclusiones del asunto Rottmann, que sea sólo una cuestión de tiempo : "La ciudadanía de la Unión constituye más que un conjunto de derechos que, en sí mismos, podrían ser concedidos incluso a quienes no la poseen. Presupone la existencia de un vínculo entre los ciudadanos europeos de carácter político, aunque no se trata de un vínculo de pertenencia a un pueblo. Antes bien, este vínculo político une a los pueblos de Europa. Se basa en su compromiso mutuo de abrir sus comunidades políticas respectivas a los otros ciudadanos europeos y de construir una nueva forma de solidaridad cívica y política a escala europea.” (apartado 23).

No obstante, no hay que olvidar que los derechos políticos estrictos - es decir derechos de voto- que los Tratados europeos se reconocen a los ciudadanos europeos, actúan a nivel europeo (es decir al Parlamento Europeo, única institución europea elegida directamente por los ciudadanos europeos) y a nivel local (y sólo en las elecciones municipales), pero no a nivel nacional, como ya hemos mencionado. El camino, pues, que queda para que los Estados miembros abran sus comunidades políticas parece todavía bastante largo.

: ARTIGO APROVADO (02/12/2012) : RECEBIDO EM 17/10/2011

\section{NOTAS}

1 Según el artículo 20 del TFUE:

“1. Se crea una ciudadanía de la Unión. Será ciudadano de la Unión toda persona que ostente la nacionalidad de un Estado miembro. La ciudadanía de la Unión se añade a la ciudadanía nacional sin sustituirla.

2. Los ciudadanos de la Unión son titulares de los derechos y están sujetos a los deberes establecidos en los Tratados. Tienen, entre otras cosas, el derecho:

a. de circular y residir libremente en el territorio de los Estados miembros;

b. de sufragio activo y pasivo en las elecciones al Parlamento Europeo y en las elecciones municipales del Estado miembro en el que residan, en las mismas condiciones que los nacionales de dicho Estado;

c. de acogerse, en el territorio de un tercer país en el que no esté representado el Estado miembro del que sean nacionales, a la protección de las autoridades diplomáticas y consulares de cualquier Estado miembro en las mismas condiciones que los nacionales de dicho Estado;

d. de formular peticiones al Parlamento Europeo, de recurrir al Defensor del Pueblo Europeo, así como de dirigirse a las instituciones y a los órganos consultivos de la Unión en una de las lenguas de los Tratados y de recibir una contestación en esa misma lengua.

Estos derechos se ejercerán en las condiciones y dentro de los límites definidos por los Tratados y por las medidas adoptadas en aplicación de éstos.” 
2 Sobre la «paternidad» de la Déclaration des Droits de L'Homme et du Citoyen y en particular la influencia de las Declaraciones americanas (Declaración de Virginia del 12 de junio de 1776 o Declaración de Independencia del 4 de Julio de 1776), véase la célebre disputa entre Jellinek y Boutmy. BOUTMY, E., “La Déclaration des droits de l'Homme et du Citoyen et M. Jellinek», Annales des Sciences Politiques, tome XVII, 1902, p 415. JELLINEK, C., "Réponse à M. Boutmy », Revue de Droit Public, tome XVIII, 1902, p 385. Más allá de esa disputa, existe toda una literatura sobre la " paternidad » de la Déclaration de 1789. Véase en particular, GARCÍA DE ENTERRÍA, E., La lengua de los derechos. La formación del derecho público europeo tras la Revolución francesa, Alianza Editorial, Madrid, 1994 ; GAUCHET, M., "Droits de l'Homme”, en FURET, F. y OZOUF M., Dictionnaire critique de la Revolution française, Flammarion, Paris, 1988; WAHL, N., « Les déclarations des colonies américaines: une autre tradition de la liberté », en COLLIARD, C.A y CONAC G., La Déclaration des droits de l'Homme et du Citoyen ses origines, sa perennité, La Documentation Française, Paris, 1990.

3 Véase GAROT, M-J., «Electeur, soldat, citoyen: les droits politiques des étrangers aux Etats-Unis, de la période coloniale aux lendemains de la Première Guerre Mondiale », Pouvoirs, nº 83, 1997, p. 151.

4 MORAVCSIK, A., « The European Constitutional Settlement », TheWorld Economy, January 2008, p 158-183.

5 Basta ver las tasas de participación de los ciudadanos europeos en las elecciones europeas para darse cuenta de lo que significa "passive citizens".

6 Acordémonos que el Tratado de Constitución Europea fue abandonado cuando, en mayo de 2005, Francia y Holanda lo rechazaron, vía referéndum en ambos casos, mientras que una mayoría de Estados miembros ya lo había ratificado.

7 GAROT, M-J y DE AREILZA J M. “Europa sin Europeos: la ratificación del Tratado de Lisboa en un contexto de crisis política”, Revista Novos Estudios Juridicos, Febrero 2009, p 26.

8 Véase en particular GAROT, M-J y DE AREILZA J M , "Europa sin Europeos: la ratificación del Tratado de Lisboa en un contexto de crisis política”, Revista Novos Estudios Juridicos, Febrero 2009.

9 RODRIK D., The Globalization Paradox- Democracy and the future of world economy, W. W Norton \& Company, 2011. Vease en particular el capitulo 9 titulado "Political trilema of the World Economy", p 184.

10 Entrevista a WEILER J. en El Mundo, lunes 9 de julio de 2012, p 22.

11 El principio de igualdad como derecho fundamental de los ciudadanos europeos ha sido reconocido tempranamente por el Tribunal de Justicia de la Unión Europea como un principio general del Derecho Europeo. Véase a este respecto la tesis muy interesante de BROTTES, J., Du príncipe de non-discrimination au príncipe d'égalité en Droit Communautaire, Université de Lyon 3, 2007. Disponible en http://theses.univ-lyon3.fr/documents/lyon3/2007/brottes_j/info.

12 ROBIN-OLIVIER, S., Le principe d'égalité en Droit Communautaire, étude à partir des libertés économiques, Presses Universitaires d'Aix-Marseille, 1999.

13 Es notable que esa misma expresión se encuentre de nuevo en el Preámbulo del actual Tratado de la Unión Europea.

14 Pagina web del Parlamento Europeo: http://www.europarl.europa.eu/parliament/expert/staticDisplay.do?language= ES\&id=43\&pageRank=1.

15 Consultable en http://www.europarl.europa.eu/sides/getDoc.do?pubRef=-//EP//TEXT+REPORT+A7-2011$0062+O+D O C+X M L+V O / / E S$.

16 Reglamento (CE) n ${ }^{\circ}$ 2004/2003 del Parlamento Europeo y el Consejo relativo al estatuto y la financiación de los partidos políticos a escala europea, DO L 297, 15.11.2003, p. 1, modificado por el Reglamento (CE) $n^{\circ} 1524 / 2007$ del Parlamento Europeo y el Consejo, de 18 de diciembre de 2007, DO L 343, 27.12.2007, p. 5.

17 En ese sentido se puede consultar un informe de Sir PRIESTLEY, J., (Secretario General del Parlamento Europeo de 1997 a 2007), European Political Parties: the missing link, Notre Europe Policy Paper 41., November 2010. 
18 Vease en este sentido el estudio de ROA BASTOS, F., Des partis politiques au niveau européen: état des lieux à la veille des élections européennes de Juin 2009, Notre Europe, Etudes et Recherche $\mathrm{n}^{\circ}$ 71, http://www.notreeurope.eu/uploads/tx_publication / Etud71-FRoaoBastos-Partiseuropens-fr.pdf.

19 Veáse lo que dice L.M DÍEZ-PICAZO en relación con la necesidad de fomentar una conciencia europea para conseguir una ciudadanía europea plena, citando entre otros a J.HABERMAS y su ya célebre concepto de "patriotismo constitucional”. DÍEZ-PICAZO, L.M., Ciudadanía e identidad europeas, IE Working Paper, 01/03 del 10 de abril de 2003.

20 Existe ya un trabajo social europeo pero es puramente optativo, en ningún caso obligatorio.

21 Financial Times Deutschland, 10 de agosto de 2010.

22 Vease DE GROOT, G-R., “Towards a European Nationality Law”, Electronic Journal of Comparative Law, vol. 8.3 (October 2004); ROSTEK, K. and DAVIES G., "The impact of Union citizenship on national citizenship”, European Integration online papers, 4 July 2006; THOMAS, E R., "Immigration and changing definitions of national citizenship in France, Germany and Britain”, French Politics, 2006, 4, 237-265.

23 Convenio de la Haya sobre algunas cuestiones en relación con conflictos de leyes en materia de nacionalidad del 12 de abril de 1930.

24 Convenio Europeo sobre la nacionalidad adoptado el 6 de noviembre de 1997 y entrado en vigor el 1 de marzo de 2000 .

25 STJ, de 7.7.1992, as Mario Vicente Micheletti (C-369/90).

26 STJ, de 19.10.2004, as. Kunqian Catherine Zhu, Man Lavette Chen contra Secretary of State for the Home Department (C200/02).

27 Según lo que explica el Tribunal de Justicia en el apartado 9 de la sentencia "Con arreglo al artículo 6, apartado 1, de la Irish Nationality and Citizenship Act 1956 (Ley de 1956 sobre la nacionalidad y la ciudadanía irlandesas), modificada durante el año 2001 y aplicable con efectos retroactivos desde el 2 de diciembre de 1999, Irlanda permite adquirir la nacionalidad irlandesa a toda persona nacida en la isla de Irlanda. Según el apartado 3 de dicho artículo, una persona nacida en la isla de Irlanda adquiere la nacionalidad irlandesa de origen si no tiene derecho a adquirir la nacionalidad de otro país."

28 STJ, de 2.3.2010, as. Janko Rottmann v. Freistaat Bayern (C-135/08).

29 Véase en particular el Working Paper de KOCHENOV, D., Rounding up the circle: the mutation of Member States' nationalities under pressure from EU Citizenship, RSCAS 2010/23, Robert Schuman Centre for Advanced Studies.

30 Sin embargo, para poder ampliar los derechos asociados a la ciudadanía europea, el Consejo de Ministros tiene que decidir por unanimidad, previa aprobación del Parlamento Europeo y ratificación por parte de los Estados miembros.

31 STJ, de 20.09.2001, as Rudy Gzelczyk (C- 184/99).

32 El articulo 7 de la directiva 2004/38 dicta exactamente: “ Derecho de residencia por más de tres meses

1. Todo ciudadano de la Unión tiene derecho de residencia en el territorio de otro Estado miembro por un período superior a tres meses si:

a) es un trabajador por cuenta ajena o por cuenta propia en el Estado miembro de acogida, o

b) dispone, para sí y los miembros de su familia, de recursos suficientes para no convertirse en una carga para la asistencia social del Estado miembro de acogida durante su período de residencia, así como de un seguro de enfermedad que cubra todos los riesgos en el Estado miembro de acogida, o

c) - está matriculado en un centro público o privado, reconocido o financiado por el Estado miembro de acogida con arreglo a su legislación o a su práctica administrativa, con la finalidad principal de cursar estudios, inclusive de formación profesional; $\mathrm{y}$

- cuenta con un seguro de enfermedad que cubre todos los riesgos en el Estado miembro de acogida y garantiza a la autoridad nacional competente, mediante una declaración o por cualquier otro medio equivalente de su elección, que 
posee recursos suficientes para sí y los miembros de su familia para no convertirse en una carga para la asistencia social del Estado miembro de acogida durante su período de residencia, o es un miembro de la familia que acompaña a un ciudadano de la Unión, o va a reunirse con él, y que cumple las condiciones contempladas en las letras a), b) o c).

2. El derecho de residencia establecido en el apartado 1 se ampliará a los miembros de la familia que no sean nacionales de un Estado miembro cuando acompañen al ciudadano de la Unión o se reúnan con él en el Estado miembro de acogida, siempre que dicho ciudadano cumpla las condiciones contempladas en las letras a), b) o c) del apartado 1 .

3. A los efectos de la letra a) del apartado 1, el ciudadano de la Unión que ya no ejerza ninguna actividad por cuenta ajena o por cuenta propia mantendrá la condición de trabajador por cuenta ajena o por cuenta propia en los siguientes casos:

a) si sufre una incapacidad laboral temporal resultante de una enfermedad o accidente;

b) si, habiendo quedado en paro involuntario debidamente acreditado, tras haber estado empleado durante más de un año, se ha inscrito en el servicio de empleo competente con el fin de encontrar un trabajo;

c) si, habiendo quedado en paro involuntario debidamente acreditado tras concluir un contrato de trabajo de duración determinada inferior a un año o habiendo quedado en paro involuntario durante los primeros doce meses, se ha inscrito en el servicio de empleo competente con el fin de encontrar un trabajo. En este caso, la condición de trabajador se mantendrá durante un período que no podrá ser inferior a seis meses;

d) si sigue una formación profesional. Salvo que se encuentre en situación de paro involuntario, el mantenimiento de la condición de trabajador exigirá que la formación guarde relación con el empleo previo.

4. No obstante lo dispuesto en la letra d) del apartado 1 y en el apartado 2, únicamente el cónyuge, la pareja registrada a que se refiere la letra b) del punto 2 del artículo 2 y los hijos a cargo tendrán el derecho de residencia como miembros de la familia de un ciudadano de la Unión que cumple los requisitos de la letra c) del apartado 1 anterior. El apartado 2 del artículo 3 se aplicará a sus ascendientes directos a cargo y a los de su cónyuge o pareja de hecho registrada”.

33 De hecho, el Tratado de Lisboa modificó el articulo 21 TCE relativo a los derechos de petición y queja al Defensor del Pueblo para incluir el derecho a una iniciativa ciudadana (art. 24 TFUE).

34 COM (2010) 119 final- Propuesta de la Comisión Europea de un Reglamento Regulador de la iniciativa ciudadana del 31 de marzo de 2010. Antes, incluso de la entrada en vigor del Tratado de Lisboa, la Comisión publicó un libro verde sobre una iniciativa ciudadana europea, el 11 de noviembre de 2009, COM (2009) 622 final.

35 El Consejo y el Parlamento Europeo adoptaron el 16 de Febrero de 2011 el Reglamento n ${ }^{\circ}$ 211/2011 relativo a la iniciativa ciudadana, DOUE, L 65/01 del 11 de marzo de 2011. El comunicado de prensa de la Comisión relativo a ese acuerdo precisa: "En el marco de una Iniciativa Ciudadana Europea, un mínimo de un millón de ciudadanos de al menos una cuarta parte de los Estados miembros de la UE podrán solicitar a la Comisión Europea que presente propuestas legislativas en ámbitos en los que sea competente para hacerlo. Los organizadores de una Iniciativa Ciudadana, un comité compuesto por al menos siete ciudadanos residentes en un mínimo de siete Estados miembros, dispondrán de un año para recoger firmas, y la Comisión tendrá un plazo de tres meses para examinar la Iniciativa y decidir la actuación correspondiente. A petición del Consejo, la legislación sobre la Iniciativa Ciudadana Europea no comenzará a aplicarse hasta que haya trascurrido un año desde su publicación en el Diario Oficial, de modo que las primeras iniciativas podrán someterse a partir de principios de 2012".

36 La Decisión 95/553 del Consejo, publicada en 1995 en el Diario Oficial (DOUE, L 314 de 28.12.1995), entró en vigor el 3 de mayo de 2002 tras un largo proceso de ratificación de los Estados miembros.

37 STJ, de 12.09.2006, as Reino de España contra Reino Unido ( C-145/04).

38 Veáse BOUGOGUE-LARSEN, L., « L'identité de l'Union Européenne au cœur d'une controverse territoriale tricentenaire. Quand le statut de Gibraltar réapparait sur la scène judiciaire européenne », Revue Trimestrielle de Droit Européen, 2007-1, p 25- 45.

39 STJ, de 23.03.2004, as. Brian Francis Collins (C-138/02).

40 STJ, de 15.03.2005, as Bidar (C-209/03). En esa sentencia, el Tribunal reconoció a un estudiante francés instalado desde menos de 5 años en el Reino Unido el beneficio de unas becas de estudio, en virtud del principio de no discriminación, a pesar del articulo 24 de la directiva del 2004 que exonera a los Estados miembros del reconocimiento de tal derecho a los ciudadanos europeos que no residen desde mas de 5 años en su territorio (a partir de 5 años de residencia, se consideran como residentes permanentes). Tres años después de esa polémica sentencia, el Tribunal hizo marcha atrás aplicando à la lettre las disposiciones del artículo 24 de la directiva. Véase la sentencia STJ, de 18.11.2008, as. Förster, (C-158/07). 
41 STJ, de 23.02.2010, as. Texeira (C 480/08).

42 STJ, de 23.02.2010, as Ibrahim (C-310/08).

43 La directiva 2004/38/CE del Parlamento Europeo y del Consejo de 29 de abril de 2004 relativa al derecho de los ciudadanos de la Unión y de los miembros de sus familias a circular y residir libremente en el territorio de los Estados miembros modifica el Reglamento (CEE) n ${ }^{\circ} 1612 / 68$ y deroga las Directivas 64/221/CEE, 68/360/CEE, 72/194/CEE, 73/148/CEE, 75/34/CEE, 75/35/CEE, 90/364/CEE, 90/365/CEE y 93/96/CEE.

44 Para un estudio profundizado de esas dos sentencias, véase BULZOMI, C. y LESKINEN C., Recent Developments on the Free movement of persons in the European Union, WP IE Law School, 10-05, 2010.

45 STJ, 8.03.2011, as. Ruiz Zambrano (C- 34/09).

46 Para la historia detallada de las múltiples solicitudes del Sr. Ruiz Zambrano, véase los apartados 14 a 34 de la sentencia.

47 STJ, de 2.10.2003, as. García Avello (C-148/02) - Se trataba de saber si unos niños con doble nacionalidad belga y española, podían pedir ante el registro civil belga el reconocimiento de unos derechos relacionados con su apellido que otorga otro Estado miembro, España, del cual el padre de esos niños, tiene la nacionalidad.

48 STJ, de 25.07.2008, as Metock (C-127/08). En esa sentencia, el TJCE hizo una interpretación de la Directiva 2004/38 que limite el margen de maniobra de los Estados miembros en la admisión de nacionales de Estados terceros.

\title{
Marie-José Garot
}

\author{
IE Law School \\ C/ Serrano 105 \\ 28006 - Madrid - Spain \\ Marie.Jose.Garotlaie.edu
}

\author{
PROFESSOR OF LAW \\ IE - JeAn MONnet ChaIR
}

Director of the Center for European Studies/IE 